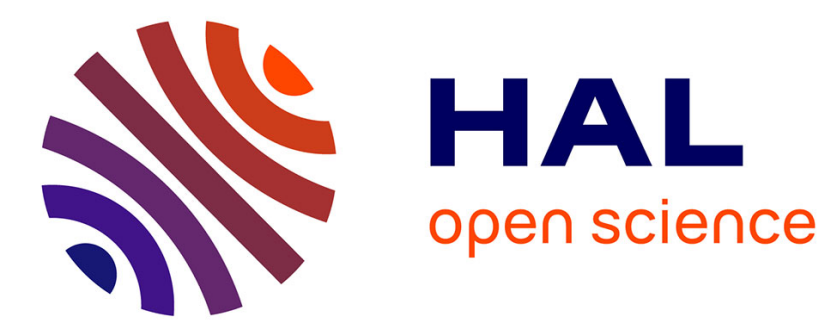

\title{
Research experimental platforms to study microgrids issues
}

\author{
Haritza Camblong, Octavian Curea, Aitor Etxeberria, Alvaro Llaria, Amélie
} Hacala-Perret

\section{- To cite this version:}

Haritza Camblong, Octavian Curea, Aitor Etxeberria, Alvaro Llaria, Amélie Hacala-Perret. Research experimental platforms to study microgrids issues. International Journal on Interactive Design and Manufacturing, 2015, 10.1007/s12008-015-0288-x . hal-01234057

\section{HAL Id: hal-01234057 https://hal.science/hal-01234057}

Submitted on 1 Dec 2015

HAL is a multi-disciplinary open access archive for the deposit and dissemination of scientific research documents, whether they are published or not. The documents may come from teaching and research institutions in France or abroad, or from public or private research centers.
L'archive ouverte pluridisciplinaire HAL, est destinée au dépôt et à la diffusion de documents scientifiques de niveau recherche, publiés ou non, émanant des établissements d'enseignement et de recherche français ou étrangers, des laboratoires publics ou privés. 
Camblong H., Curea O., Etxeberria A., Llaria A., Hacala A., "Research experimental platforms to study microgrids issues". IJDEM, 2015, Online ISSN 1955-2505, Springer Paris, DOI 10.1007/s12008-015-0288-x

\title{
Research experimental platforms to study microgrids issues
}

\author{
CAMBLONG Haritza ${ }^{12}$, CUREA Octavian ${ }^{1}$, ETXEBERRIA Aitor ${ }^{1,2}$, \\ LLARÍA Alvaro ${ }^{1}$, HACALA PERRET Amélie ${ }^{1}$ \\ 'ESTLA, F-64210 Bidart, France \\ $+33.5 .59 .43 .84 .00 /+33.5 .59 .43 .84 .01$ \\ E-mail: h camblong(a)estia.fr, o.curea@estia.fi, \\ a.etxeberria@estia.fr, a.llaria@estia.fr, a.hacala@estia.fi \\ ${ }^{2}$ Department of Systems Engineering \& Control, \\ University of the Basque Country (UPV/EHU), \\ Europa Plaza 1, Donostia-San Sebastián 20018, Spain
}

\begin{abstract}
Microgrid (MG) concept is becoming increasingly mature. It allows integrating better distributed generation, and especially renewable energy sources, in the grid. However, many issues have still to be resolved before implementing this concept in the real power system extensively. This paper presents first a review of the main issues associated to microgrids dealt with in the scientific literature. The different issues are classified and some examples of carried out studies are given for each issue. Then, a short review of existing experimental microgrids is done. They are classified in smallsize and real-size experimental MGs. After that, the EneR-GEA experimental MG or platform of ESTIA Engineering School is presented, describing its different components. Then, some carried out experiments are explained. To finish, the main planned projects at short and medium term related to this platform are given.
\end{abstract}

Keywords: Microgrids, renewable energies, energy management optimization, islanding, power quality, storage systems, experimental platform. 
Camblong H., Curea O., Etxeberria A., Llaria A., Hacala A., 'Research experimental platforms to study microgrids issues". IJIEM, 2015, Online ISSN 1955-2505, Springer Paris, DOI 10.1007/s12008-015-0288-x

\section{Introduction}

For different reasons, power systems are evolving these last years. More intelligence is introduced in them, hence the term smartgrid. Firstly, this evolution is due to the growth of distributed generation (DG). DG represents decentralized electric generators, above all installed in distribution grids. These generators have a rather low power. They are often fed from renewable energy sources (RES) (wind turbines (WT), PV panels, fuel cells (FC)...), but also from fossil fuels (micro-turbines (MT), diesel engines). The fact that DG is decentralized and that it is largely from RES, thus stochastic and intermittent, disturbs the operation of classical grids.

Secondly, the development of information and communication technologies, power electronics, storage systems and control engineering and artificial intelligence (AI) contribute to the evolution of power systems. They make grids more flexible and intelligent, with a significant improvement potential of efficiency, security, cost and adaptability.

There exist more and more propositions to organize some power system parts as microgrids (MGs), in particular in nural or island regions. This new organization allows optimizing the grid and makes it more robust, while facilitating the integration of DG.

\subsection{Microgrids and smartgrids}

Smartgrids and MG concepts are relatively new but they are being defined more thoroughly in the scientific literature. According to [1], "a microgrid is a local island grid that can operate as stand-alone or as grid-connected system. It is powered by gas turbines or RES and includes special purpose inverters and a link for plug-and-play to the legacy grid". Moreover, the author sees the MG as a "local power provider with limited advanced control" and the smartgrid as a "wide area provider with sophisticated automated decision support capabilities".

However, the intelligence or smartness of MGs is often emphasized, as in [2], where MGs are defined as low or medium voltage intelligent distribution networks comprising various DGs, storage systems and controllable loads which can be operated as interconnected to the main distribution grid or as islanded if disconnected from the main grid. Actually, a MG can be seen as part of a power system which will help to transform the traditional grid in a smartgrid, or as mentioned in [3], "the indispensable infrastructure of nowadays smartgrid". Several microgrids architectures have been proposed in the literature. One of the first is presented in [4]. An example of a basic structure of a MG is shown in Figure 1. In this Figure, the energy manager is the only component which communicates with the main grid manager, so the microgrid is seen as an only entity from outside. The point of common coupling (PCC) is the power connection between the microgrid and the main grid. For the data exchange between the energy manager and the other components of the MG, a communication network is 
necessary. This network can be used to transmit not only control signals but also measured data [5].

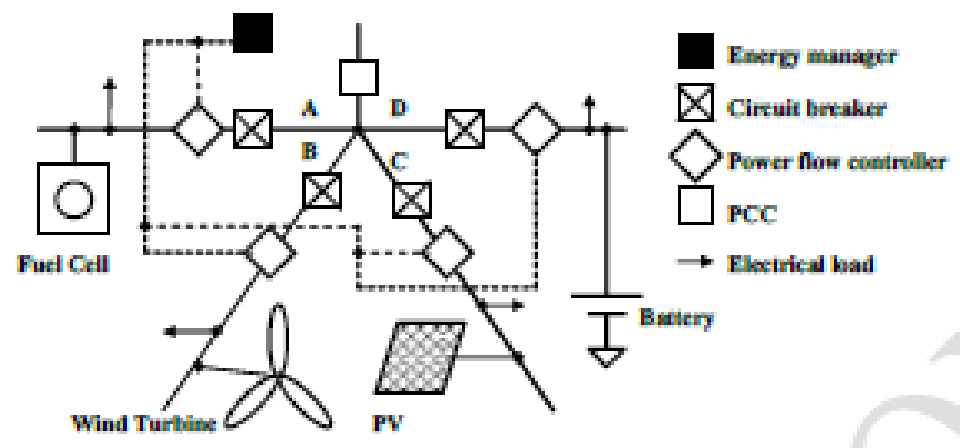

Figure 1. Basic architecture of a MG.

The main objective of MG concept is to make easier the integration of DG in medium voltage (MV) and low voltage (LV) distribution grids, but it may bring benefits far beyond that: the reduction of energy costs, the improvement of the reliability of the grid, the provision of ancillary services, the deferral of investments in the distribution network and the reduction of losses [6], but also the environmental performance and the lower exposition to catastrophic failures in the power system [7].

\subsection{Microgrids' research issues}

Many problems related to MGs are studied in the scientific literature. This section deals with the main issues. Some carried out research studies are presented to illustrate each topic.

\subsubsection{Energy management optimization}

One of the main topics related to MGs is the optimization of their energy management. Some papers, as $[8,9,10]$ deal with MGs in grid-connected mode. In [9] an online active power optimized dispatch is proposed using different non-linear programming tools. The dispatch is shared between diesel engines, FCs and MTs, while renewable microsources work at the maximum power that the environmental conditions allow. Generation costs and $\mathrm{CO}_{2}$ emissions are minimized. The execution time being very low ( $1 \mathrm{~ms})$, the developed software tool can be easily programmed and run on-line in a low-cost programmable logic controller. Reference [8] deals with the optimal generation scheduling of distributed energy resources (DER), such as DG and storage, in tertiary regulation, with the aim of minimizing carbon emissions and production costs (through reduction of energy losses and fuel consumption), and maximizing power quality (for instance limiting voltage drops). The scheduling is adaptive and takes into account load and renewable generation prevision errors to re-plan the tertiary regulation. 
Camblong H., Curea O., Etxeberria A., Llaria A., Hacala A., 'Research experimental platforms to study microgrids issues". IJDEM, 2015, Online ISSN 1955-2505, Springer Paris, DOI 10.1007/s12008-015-0288-x

Reference [10] analyzes the behavior of Hong's point estimate method to account for uncertainties (market prices, load demands and electric power generation) in probabilistic energy management systems to optimize the operation of a grid-connected microgrid.

Other papers deal with MGs working in islanded mode. In [11] a modified conventional energy management algorithm based on local energy market is proposed to reduce generated power global costs and ensure uninterruptable power supply services. Tests carried out on an experimental MG containing WTs, PV panels, MTs, energy storage systems, controllable electric water heater and non-controllable loads show the efficiency of the proposed algorithm. In [12] a multi-agent system for energy resource scheduling is described. The studied grid is made up of five lumped loads and three MGs considered as autonomous subsets. A three-stage algorithm is designed and tested in simulations, showing an efficient management of micro-sources with minimum operational cost. The proposed multi-agent system is scalable, robust and easily reconfigurable. In [13], a polygeneration $\mathrm{MG}$ is analyzed. On top of considering power management, water and hydrogen management is also taken into account. Thanks to an optimizing algorithm based on fuzzy logic, the available energy is better used. The components' sizes are, thus, considerably decreased, leading to a cheaper MG.

According to $[14,15]$, ancillary services (ASs) market could be a great opportunity for both, DG and MGs, especially for voltage control and reserve provision. In [16] an AS market framework addressing voltage control in multi-MGs systems is presented. The market settlement is performed using an optimal power flow (OPF) formulation in order to minimize the price of reactive power purchased by the distribution system operator (DSO), considering certain operational and security criteria. Thus, a MG can be operated similarly to a virtual power plant from the MV distribution system, and the MG central controller will act as an aggregator collecting bids from several DER connected to the LV network

\subsubsection{Hybridization}

Other research studies focus on smaller aggregation of generation and storage units named hybrid energy systems (HES) and managed as MGs. In [17] a HES made up of WTs, PV panels and batteries connected to a common DC bus is managed to act as a grid AS provider instead of a stochastic and dynamically unpredictable energy generator. The proposed solution, validated by results obtained on an experimental setup, maintains a constant power flow with the grid/load and behaves as a sort of spinning reserve. In reference [18] a review of hybrid FCs technologies considered as components of MGs is carried out. Authors show how hybridization allows reducing cost and pollution and increasing efficiency and flexibility. Three kinds of hybridization are studied: FCs with MTs, different types of FCs together (SOFC and PEMFC), and 
Camblong H., Curea O., Etxeberria A., Llaría A., Hacala A., 'Research experimental platforms to study microgrids issues". IJDEM, 2015, Online ISSN 1955-2505, Springer Paris, DOI 10.1007/s12008-015-0288-x

FCs with WTs and PV panels.

Hybridization can also be carried out between different $\mathrm{AC}$ and $\mathrm{DC}$ lines. For instance in [19] an AC/DC MG structure is proposed in order to ease the integration of RES. Every intermittent domestic generator is connected to a $\mathrm{DC}$ line named generation line. An energy conversion station is situated in the $\mathrm{PCC}$. It converts $\mathrm{AC}$ utility power in $\mathrm{DC}$ power and dispatch, via switches and a DC/AC converter, the power coming from the generation line and utility to the consumption line. This structure facilitates control and management operations, specially islanding and synchronization, and it improves robustness and quality of $\mathrm{AC}$ power distribution in the $\mathrm{MG}$.

\subsubsection{Islanding}

An inherent characteristic of MGs is their capacity to be islanded from the main grid. This capacity leads to an improvement of the reliability to feed internal and external consumers [7]. Indeed, the rate and the duration of the interruptions decrease for internal consumers, while the internuptions can be shortened for consumers outside the MG.

On the other hand, as written in [20], the islanding of the MG can be intentional (planned) or unintentional (unplanned). The second case is the most difficult to manage. Indeed, the islanding must be detected in order to allow operating the MG. There are three main types of islanding detection techniques: passive methods, active methods and utility level methods [21,22]. All of them must accomplish the standards IEEE 1547 [23], IEEE 929-2000 [24] and UL 1741 [25]. As explained in [20], passive islanding detection algorithms operate measuring local values of voltage, frequency or phase. They are technologically neutral and the cheapest solution, but their effectiveness is not the best. On the other hand, active algorithms employ varied techniques such as injection of active signals. In [26], an active islanding detection technique suitable for current controlled inverters is presented. The method is based on changing the magnitude of the injected current and monitoring the voltage at the PCC. Comparing with passive techniques, they are considered more effective to detect islanding, but they are more expensive and not technologically neutral [20].

Finally, utility level methods employ techniques based on communication signals (such as SCADA) or different alarms to detect the islanding. In this context, solutions based on communicating multi agents can be also applied in order to detect the disconnection from the main grid, as it is shown in [27]. The described method proposes a decentralized hierarchical management system for microgrids which allows not only the detection of islanding, but also the latter synchronization between the microgrid and the main grid, necessary to perform a seamless reconnection.

\subsubsection{Demand side management}

Demand side management (DSM) is another significant topic related to MGs, 
Camblong H., Curea O., Etxeberria A., Llaria A., Hacala A., "Research experimental platforms to study microgrids issues". IJIDEM, 2015, Online ISSN 1955-2505, Springer Paris, DOI 10.1007/s12008-015-0288-x

especially in islanded mode. In [28], as in [13], a Greek island's autonomous polygeneration MG is examined. It is made up of WTs, PV panels, batteries, a desalination system, an electrolyzer and three houses. A multi-agent based optimal energy, water and hydrogen management system, with DSM which considers load priorities, allows a more effective working of the MGs and thus a best and cheaper sizing. In order to provide to the microgrid the DSM capability, it is necessary to be able to connect or disconnect each load or group of loads (with the same priority). Thus, even if the amount of data to be exchanged is not excessive, a communication network is necessary. In this context, low cost communication solutions can be considered.

\subsubsection{Primary regulation with converters in parallel}

Once islanded, MG primary voltage and frequency primary regulation is a significant issue. In [29], a review on this matter is carried out, for MGs with power electronics interfaces. Most DG units are power electronically interfaced to the grid. DG units can be classified in grid-forming or grid-following units. The paper deals with the control strategies for grid-forming converters and distinguishes communication-based controllers from controllers without communication. Among communication-based ones, the most current are central and master/slave controls. These kinds of controllers achieve good voltage regulation and power sharing. However, communication lines are expensive and vulnerable, they reduce the system reliability and expansibility and they limit its flexibility. Concerning control strategies without communication, they are based on droop control. They make easier to achieve redundancy and avoid the complexity, high cost and the requirement of high reliability of a supervisory system. Moreover, the modules have plug-and-play feature, and thus can be easily expanded. The main drawbacks of these strategies are the trade-off between power sharing accuracy and voltage deviations, unbalance in harmonic current sharing and dependency on the inverter output impedance. On the other hand, MGs are often low-voltage networks, and as explained in [29], low-voltage networks are mainly resistive, leading to the usage of $P / V$ and $Q / f$ droop controllers, instead of $P / f$ and $Q / V$ ones ( $P$ is the real power, $V$ the voltage, $Q$ the reactive power and $f$ the frequency). In [30], single master and multi master operations are tested. Simulation results show that both control strategies are effective and ensure efficient and stable MG operation Furthermore, the results suggest that the management of storage devices is absolutely essential to implement successful control strategies for MG operation in islanded mode.

\subsubsection{Energy storage systems}

Energy storage is the fundamental component of MG [3]. It allows addressing different issues as short term power supply (for instance to avoid momentary outages), facilitating integration of RES, arbitrage (storage of energy when it is cheap and re- 
dispatching when it is expensive, similar to peak shaving or time shifting in [31]), optimizing of microsource in MG (smoothing transitions), power quality improvement (high power factor, suppression of harmonics distortions...) and ASs (load following, operational reserve, frequency regulation...). Different kinds of energy storage systems (ESS) are needed to address the aforementioned issues, some with very low response time and others with high energy capacity. Most common ESS providing fast response and high power density are supercapacitors (SCs), flywheels and superconducting magnetic energy storage systems, while batteries are the ESSs with highest energy density and capacity [3]. Flow batteries, compressed air energy, pumped hydro storage and hydrogen-based energy storage systems have a very big energy capacity potential [31].

On the other hand, there are two typical configurations of ESSs in a MG, the aggregated one and the distributed one. Different topologies of power electronics interface for ESSs exist, associating in general DC/DC and DC/AC converters [3]. They depend on the type of ESSs and their configuration. Furthermore, the design of versatile ESSs having capability to operate in wide ranges of power density and energy density is required [32]. Since no single energy storage technology has this capability, hybrid ESSs incorporating combinations of technologies aforementioned have to be designed. Different types of ESSs can be associated between them, but also to DG or flexible AC transmission systems (FACTS), using power electronics, communication interface, controllers and power management algorithm, and thus leading to smart ESSs concept [3]. For instance in [31] the association of intelligent ESSs to WTs is analyzed. The optimal selection of the used ESS depends on the objective of the association: fluctuation suppression, low voltage ride through, voltage control support, oscillation damping, spinning reserve, load following, peak shaving, transmission curtailment, time shifting, unit commitment or seasonal storage.

Thermal storage has also been presented as an interesting alternative to improve the penetration level of renewable energy sources in the case were thermal load are installed in the microgrid, namely water tanks. An electric water heater system can be used as a controllable load that can help to absorb the generation peaks of the renewable sources [33]

\subsubsection{Power quality and transients}

Power quality is also a significant issue on MGs. Indeed, MGs are set in the distribution network which is full of voltage disturbances. Furthermore, when islanded or embedded [34], MGs are more vulnerable and unstable. Some significant voltage disturbances happening in MGs are [35]: transient overvoltages; unbalanced voltages; voltage dips and short interruptions; voltage fluctuations; disturbances in generation units such as variations of the generation of non-dispatchable units; and islanding and 
reconnection of the MG to the utility. Moreover, non-linear loads can increase the harmonic level of the MG's current and voltage [36]. Controllers with high dynamics as for instance sliding mode controllers [35] have to be used to overcome the above mentioned disturbances.

Conceming voltage and current unbalance problem, it is especially important in islanded MGs where single-phase loads and sources (for instance PV panels) are connected. When the system is unbalanced, the negative sequence components corresponding to the symmetrical component theory proposed by Fortescue [37] is not zero. The voltage of the MG suffering high values of negative sequence component leads to increased losses and poor power quality for the connected loads [36], which can be a problem especially for all induction motors [38]. Voltage unbalance can be faced from different ways. For instance in [36], the negative sequence component of the voltage is controlled at zero using a time-domain based controller. In [38], one of the DG of a MG is used as a power quality compensator for unbalances and harmonics. Through a voltage source inverter consisted of three single-phase H-bridges using IGBTs, the compensator supplies a current to PCC that balances the voltage at PCC.

\subsection{Short review of existing platforms}

Innovative solutions corresponding to above mentioned issues are not directly tested in the real grid. These solutions are normally first developed and tested in numerical simulations. Then, they are usually validated in experimental MGs or platforms.

The next subsections compile some of the most relevant experimental MGs all over the world [39-43]. Several criteria can be employed in order to classify MGs (connected or not to the main grid, voltage level, etc.). In this paper, MGs have been classified into 2 categories: small-size (the power of most of elements is under $100 \mathrm{~kW} / 100 \mathrm{kVA}$ ) and real-size experimental MGs (based mainly on elements over $100 \mathrm{~kW} / 100 \mathrm{kVA}$ of power). For the first category, some of the MGs mainly use emulators, whereas others do not use emulated elements.

\subsubsection{Small-size experimental MGs}

The MG installed in the University of Athens (NTUA, Greece) and in the University of Kassel (DEMOTEC MG) [44] are two relevant examples of small-size experimental MGs. In both cases, they are composed of different kinds of sources (PV panels, WT, diesel generators) and loads, as well as ESSs. The DEMOTEC platform also includes virtual batteries, a grid emulator and a WT simulator. The power of these MGs is in the order of 1-5 kW. In the USA, the CERTS Project (Consortium for Electric Reliability Technology Solutions) has developed two MGs, one of small-size in the Wisconsin University, and another one of real-size in the Dolan Technology Center, in Ohio, which will be described later. 
Camblong H., Curea O., Etxeberria A., Llaria A., Hacala A., "Research experimental platforms to study microgrids issues". IJIDEM, 2015, Online ISSN 1955-2505, Springer Paris, DOI 10.1007/s12008-015-0288-x

Some experimental MGs include also thermal storage and loads, as that of the Department of Electrical and Electronic Engineering of the Public University of Navarre [33].

Several small-size experimental MGs are largely based on emulators. Thus, most components (DG, loads, ESSs etc.) dynamical behavior is simulated in a real-time board and transferred to the electric lines through power amplifiers. The Catalonia Institute for Energy Research (IREC) has a MG composed of different emulated configurable elements, such as the nodes, the generators (renewable or conventional), the loads (controllable and non-controllable) [45]. Another example is the DG and MGs test facility of Pozo Izquierdo, Gran Canaria, in Canaries islands.

The MG of Tecnalia (Bilbao, Basque Country), in operation since 2004, includes classical devices (PV panels, wind-turbine, batteries, etc.) as well as a grid emulator/fault generator.

\subsubsection{Real-size experimental MGs}

Real-size experimental MGs provide a power generation between $100 \mathrm{~kW}$ and 1 MW. The real-size experimental CERTS MG [46] is exploited by American Electric Power. It is composed of three feeders (two of them can be islanded) and three $60 \mathrm{~kW}$ diesel generators. The Mad River MG is another example in the USA. This MG was installed by Northern Power Systems in order to provide energy to the central office of the enterprise.

In Canada, the main efforts in MG research have been piloted by the Natural Resources Ministry (NRCan) $[47,48]$. In this context, three MGs can be highlighted: the Fortis-Alberta MG, the British Columbia Hydro Boston Bar and the Hydro Québec MG. All of them are connected to the main grid, and they can be islanded under special conditions.

It is also possible to find real-size MGs in Japan, where the research activities in this area have been leaded by the New Energy and Industrial Technology Development Organization (NEDO). Some interesting MGs which can be cited are the Aichi Project, Kyotango Project, Hachinohe Project and Sendai Project [49-52].

In China, one of the most interesting MG has been deployed by the HeFei University of Technology (HFUT) [53].

Finally, some real-size MGs can be found in Europe [54], such as Kythnos MG (a real MG that provides energy to a Greek island), Continuon (Netherlands) and CESI Ricerca (Italy). In all cases, the power generation of the presented MG is around 100 $\mathrm{kW}$. Among European MGs, the University of Genoa smart polygeneration microgrid test-bed facility has also to be mentioned [55].

\subsection{Interactive design of microgrids using experimental platforms}


Interactive design is a concept which can be applied to different knowledge areas. As it can be understood from its name, the concept is linked to systems where different components which can be human, software or hardware type, interacts between them (communication, action, decision making...) in order to design or redesign something.

In a MG experimental platform, interactions between humans, software or hardware are omnipresent. These platforms are generally used in the design process of MGs components (sources, power converters, storage systems...) and the associated control algorithms, communication systems, operation and management strategies... The experiments carried out in these platforms are part of the design process. These experiments are normally made after simulations' tests, as part of a rapid prototyping. They allow experimental evaluation of the carried out designs, often at a lower power level than that of the real studied MG.

\section{Description of the EneR-GEA experimental platform}

EneR-GEA is both, a research team and an experimental platform of ESTIA engineering school. The platform comes from a HES [56-58] installed in 2004 and has been significantly improved since 2008 . It is composed by electrical sources, loads, storage elements, converters, instrumentation and control boards. The implemented structure provides much flexibility. Thus, the platform can be easily adapted to the experiments to be carried out. It is classified as small-size experimental MG.

From the electrical point of view, the platform is organized around two AC buses (3 phases + neutral) and two DC buses (Figure 2). The two AC buses give the possibility to take into account the existence of an electrical line between different parts of the MG. The connection to the main grid is also possible. On the DC side, the first bus is directly connected to batteries $(24 \mathrm{~V})$, while the voltage of the second one is fixed with a $\mathrm{DC} / \mathrm{DC}$ converter. 
Camblong H., Curea O., Etxeberria A., Llaria A., Hacala A., "Research experimental platforms to study microgrids issues". IJIDEM, 2015, Online ISSN 1955-2505, Springer Paris, DOI 10.1007/s12008-015-0288-x

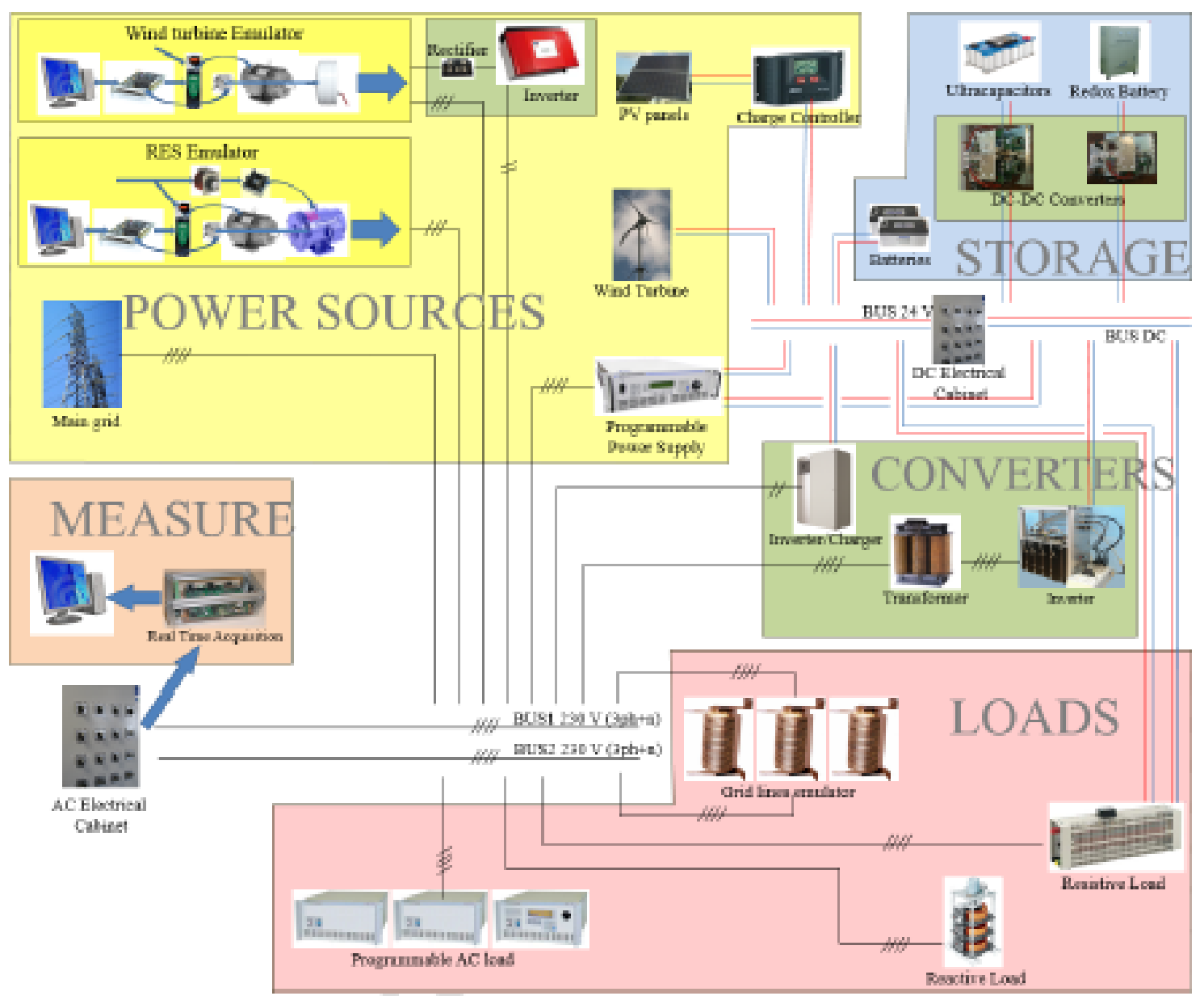

Figure 2. Architecture of the EneR-GEA MG.

\subsection{Sources}

Three kinds of power sources are available on the platform: real sources (wind turbine and PV panels), a programmable power supply and emulators. Table 1 shows the main characteristics of these sources. 
Camblong H., Curea O., Etxeberria A., Llaria A., Hacala A., "Research experimental platforms to study microgrids issues". IJIEM, 2015, Online ISSN 1955-2505, Springer Paris, DOI 10.1007/s12008-015-0288-x

Table 1. Characteristics of the different sources

\begin{tabular}{|l|l|}
\hline \multicolumn{1}{|c|}{ Power sources } & \multicolumn{1}{|c|}{ Characteristics } \\
\hline BPSolar BP3160S PV Panels & $\begin{array}{l}2 \times 160 \mathrm{~W} \text { (MPPT: } 35.1 \mathrm{~V} / \\
4.55 \mathrm{~A})\end{array}$ \\
\hline Southwest Windpower Air-X WT & $400 \mathrm{~W}$ at $12,5 \mathrm{~m} / \mathrm{s}, 24 \mathrm{~V}$ \\
\hline $\begin{array}{l}\text { CALIFORNIA INSTRUMENTS 2253iX } \\
\text { programmable power supply }\end{array}$ & $\begin{array}{l}2.25 \mathrm{kVA}, 0-300 \mathrm{~V}, 20 \mathrm{~A}, \mathrm{AC} \\
\& \mathrm{DC}\end{array}$ \\
\hline WT emulator & $1800 \mathrm{~W}$ \\
\hline RES emulator & $3 \mathrm{~kW}$ \\
\hline
\end{tabular}

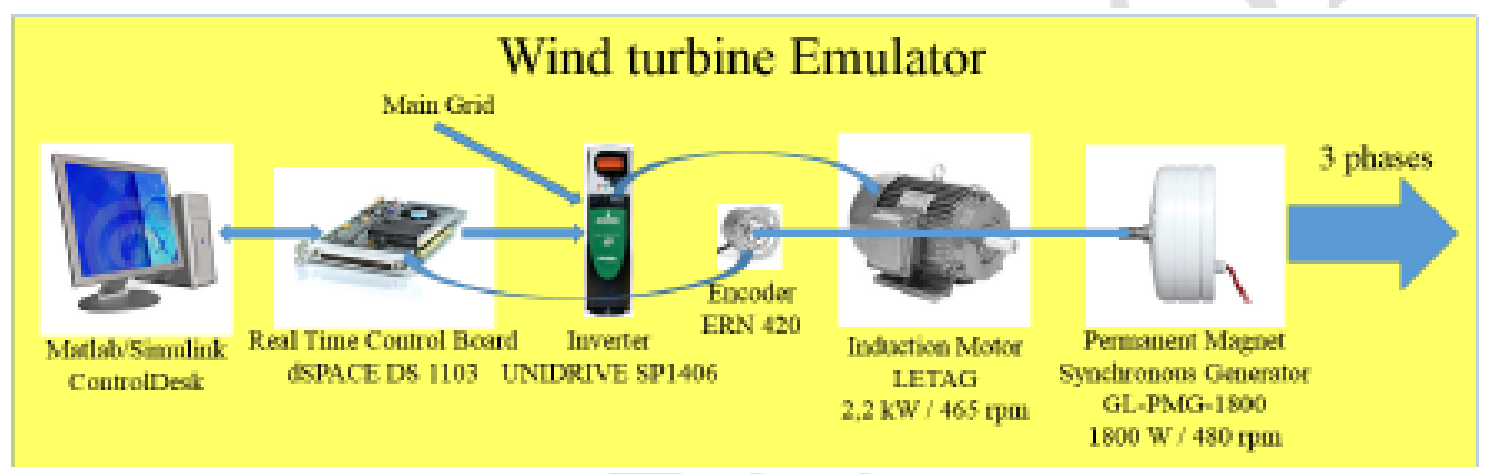

Figure 3. Wind turbine emulator.

The WT emulator depicted in Figure 3 is based on an induction motor and a permanent magnet synchronous generator. The induction motor is supplied by an inverter that receives set points from a real time control board in order to emulate a WT. The set point can be the WT shaft torque or a rotational speed simulated in the real time control board. The emulator is composed by:

LETAG induction motor: $2.2 \mathrm{~kW}, 465 \mathrm{rpm}$;

GL-PMG-1800 permanent magnet synchronous generator: $1800 \mathrm{~W}, 480 \mathrm{rpm}$;

UNIDRIVE SP1406 inverter: $5.5 / 4 \mathrm{~kW}, 11 / 9.5 \mathrm{~A}$;

dSPACE DS 1103 real-time control board.

The RES emulator has nearly the same structure as the WT emulator. The differences are at the level of the used electrical machines:

SIEMENS induction motor: $3 \mathrm{~kW} ; 1420 \mathrm{rpm}$;

LETAG wounded-rotor synchronous generator: $3 \mathrm{kVA}, 1500 \mathrm{rpm}$

\subsection{ESSs}

The installed ESSs are listed in Table 2 . They have complementary reaction times and capacities. 
Camblong H., Curea O., Etxeberria A., Llaria A., Hacala A., 'Research experimental platforms to study microgrids issues". IJDEM, 2015, Online ISSN 1955-2505, Springer Paris, DOI 10.1007/s12008-015-0288-x

Table 2. Characteristics of the ESSs

\begin{tabular}{|l|l|}
\hline \multicolumn{1}{|c|}{ ESS } & \multicolumn{1}{c|}{ Characteristics } \\
\hline LIFELINE GPL8DL deep cycle batteries & $2 \times 12 \mathrm{~V} / 255 \mathrm{Ah}(\mathrm{C} 20)$ \\
\hline MAXWELL BMOD0083 supercapacitors & $83 \mathrm{~F}, 48 \mathrm{~V}, 61 \mathrm{~A}, 26.6 \mathrm{Wh}$ \\
\hline GEFC vanadium redox flow battery & $25 \mathrm{~V} / 50 \mathrm{~A} ; 0.75 \mathrm{~h}$ \\
\hline
\end{tabular}

\subsection{Power converters}

$\mathrm{DC} / \mathrm{DC}$ converters are used to connect ESSs to the $\mathrm{DC}$ buses. $\mathrm{DC} / \mathrm{AC}$ converters (inverters) have the capacity to work as grid-formers or grid-followers, or both. Table 3 shows the power converters' characteristics.

Table 3. Characteristics of the power converters

\begin{tabular}{|l|l|}
\hline \multicolumn{1}{|c|}{ Power converters } & \multicolumn{1}{c|}{ Characteristics } \\
\hline $\begin{array}{l}\text { SMA WINDY BOY WB3000 grid-follower } \\
\text { inverter }\end{array}$ & $\begin{array}{l}\text { DC (max): 600 V / 12 A AC: } \\
2750 \mathrm{~W} / 12 \mathrm{~A}\end{array}$ \\
\hline ARCEL bidirectional DC-DC converter & $48 \mathrm{~V} / 70 \mathrm{~V}, 100 \mathrm{~A}$ \\
\hline ARCEL bidirectional DC-DC converter & $24 \mathrm{~V} / 70 \mathrm{~V}, 50 \mathrm{~A}$ \\
\hline XANTREX hybrid inverter/charger & $24 \mathrm{~V} \mathrm{DC} / 230 \mathrm{~V} \mathrm{AC}, 50 \mathrm{~Hz}$, \\
& $3 \mathrm{ph}+\mathrm{n}$ \\
\hline EneR-GEA inverter & $70 \mathrm{~V} \mathrm{DC} / 23 \mathrm{~V} \mathrm{AC}, 25 \mathrm{~A} 50$ \\
& $\mathrm{~Hz} 3 \mathrm{ph}+\mathrm{n}$ \\
\hline ARCEL Three-Level Neutral Point Clamped & $70 \mathrm{~V} / 23 \mathrm{~V}, 50 \mathrm{~A}, 50 \mathrm{~Hz}, 3 \mathrm{ph}$ \\
(3LNPC) converter & $\mathrm{n}$ \\
\hline
\end{tabular}

\subsection{Loads}

Table 4 lists the different types of loads contained in the experimental MG.

Table 4. Characteristics of the loads

\begin{tabular}{|l|l|}
\hline \multicolumn{1}{|c|}{ Loads } & \multicolumn{1}{c|}{ Characteristics } \\
\hline $\begin{array}{l}\text { CALIFORNIA INSTRUMENTS } \\
\text { programmable AC loads, } 1 \times 3091 \mathrm{LD}+ \\
2 \times 3091\end{array}$ & $\begin{array}{l}3 \times 3000 \mathrm{~W}, 50 \text { to } 350 \mathrm{~V}, 45 \mathrm{~Hz} \\
\text { to } 440 \mathrm{~Hz}\end{array}$ \\
\hline Variable resistive loads & $\begin{array}{l}640 \mathrm{~W} \text { (mono) and } 1900 \mathrm{~W} \text { (tri), } \\
\text { different values }\end{array}$ \\
\hline Variable reactive loads & $\begin{array}{l}4000 \quad \text { VAR (incuctive and } \\
\text { capacitive) }\end{array}$ \\
\hline
\end{tabular}

\subsection{Signals measurement and data-acquisition and control boards}


The visualization and recording of the significant signals are made with a NATIONAL INSTRUMENTS NI sbRIO-9641 real-time acquisition board and a LabView interface. dSpace DSP Boards are used in particular to emulate RESs.

An OP5600 Hardware-In-the-Loop simulator of Opal-RT manufacturer is used to carry out real-time simulations as well as rapid control prototyping applications. This system is used to experimentally test the control algorithms that regulate the IGBTs of the different power converters that are available in the EneR-GEA platform.

\section{Carried out experiments/studies in the EneR-GEA platform}

The following subsections depict the most significant tests carried out in the EneRGEA platform

\subsection{Voltage unbalance}

A four-leg inverter able to manage unbalanced load conditions in micro-grids applications has been designed, built and investigated (Figure 4) in the frame of a $\mathrm{PhD}$ carried out with the University of the Basque Country (UPV/EHU) and the University of Le Havre (France). This topology involves an additional leg, expanding the control capabilities of the inverter using the same DC-link capacitor and voltage and provides a path for the neutral current when the load is unbalanced.

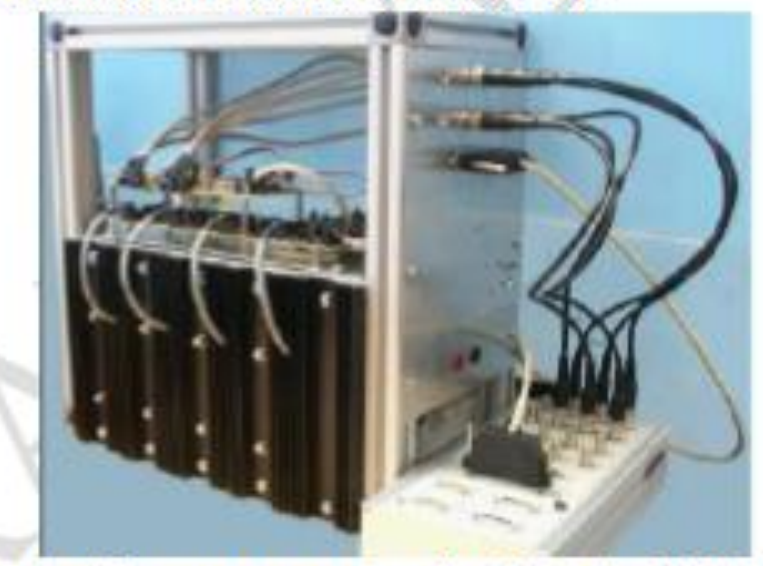

Figure 4. Inverter prototype developed in EneR-GEA.

The four-leg inverter has been controlled using an innovative control strategy based on the decomposition of the supply three-phase voltage and current into instantaneous positive, negative and homopolar sequence components using phasor representation [59]. The proposed control strategy has the ability to decompose into dq DC quantities not only the positive and negative current and voltage sequences, but also the homopolar sequence. Consequently, regulation has been easily done with classical PIcontrollers. The eight duty cycles driving the four legs of the investigated inverter are correctly generated owing to a discontinuous $3 \mathrm{D}$ SVM based on $\mathrm{ABC}$ coordinates [60]. 
Camblong H., Curea O., Etxeberria A., Llaria A., Hacala A., "Research experimental platforms to study microgrids issues". IJIEM, 2015, Online ISSN 1955-2505, Springer Paris, DOI 10.1007/s12008-015-0288-x

Figure 5 shows the inverter output current and voltage during a transient under balanced/unbalanced resistive load conditions. During approximately $1.045 \mathrm{~s}$, the threephase resistive load is heavily unbalanced. The phase B is loaded with $36 \mathrm{~W}$, and the phases A and C are loaded with $360 \mathrm{~W}$. After approximately $1.045 \mathrm{~s}$, the phase B reaches the same power as the phases $\mathrm{A}$ and $\mathrm{C}$, and the load becomes almost balanced (the total power required by the load is $1080 \mathrm{~W}$ ). As shown in Figure 5, even with unbalanced loads, the voltage is balanced.

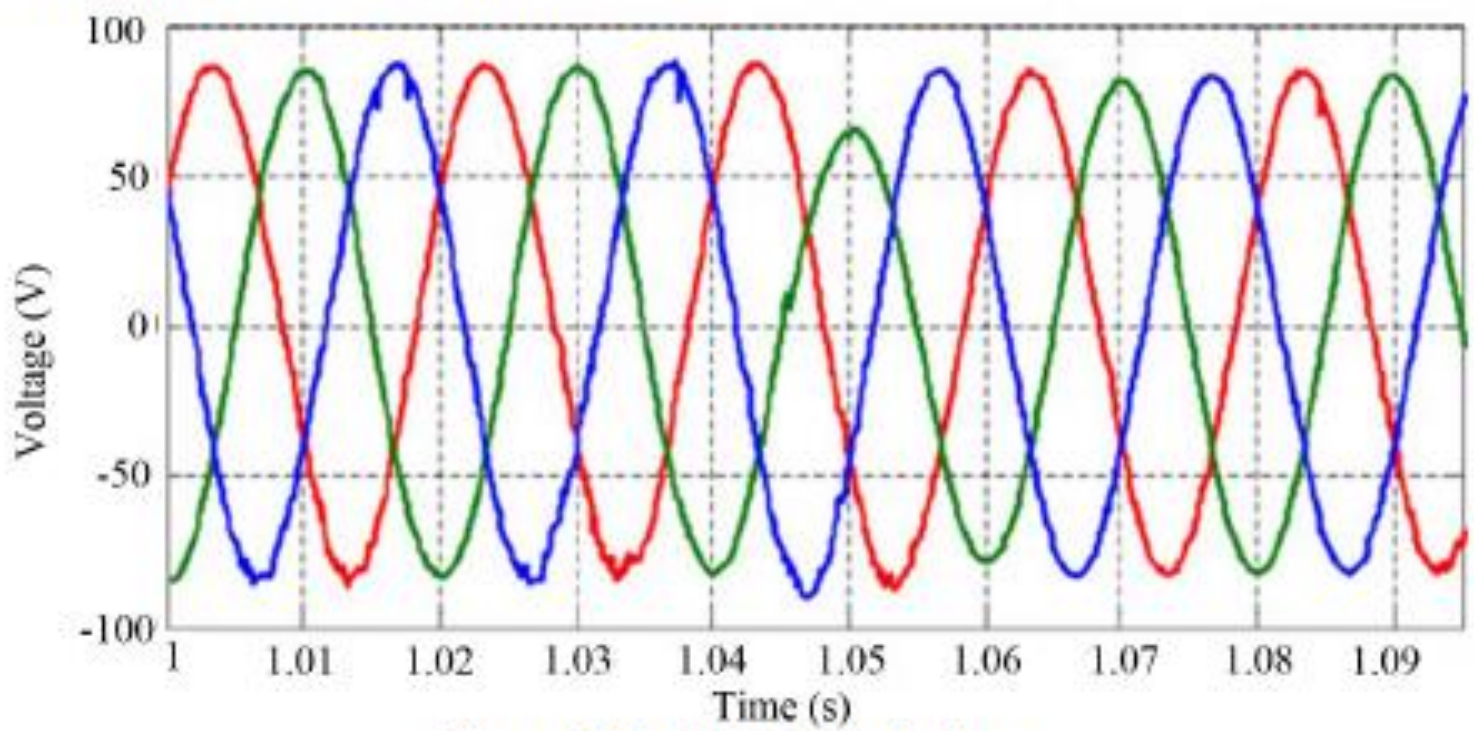

Figure 5. Load current and voltage.

\subsection{ESSs association}

During a $\mathrm{PhD}$ carried out with the University of Bordeaux (UBX, France), a hybrid ESS formed by SCs and a vanadium redox battery (VRB) has been used to experimentally validate a novel topology in the context of MGs, which is based on the use of a three-level neutral point clamped (3LNPC) converter [61]. As Figure 6 shows, both storage devices have been connected in series in order to create the DC bus of the 3LNPC topology. 
Camblong H., Curea O., Etxeberria A., Llaría A., Hacala A., 'Research experimental platforms to study microgrids issues". IJDEM, 2015, Online ISSN 1955-2505, Springer Paris, DOI 10.1007/s12008-015-0288-x

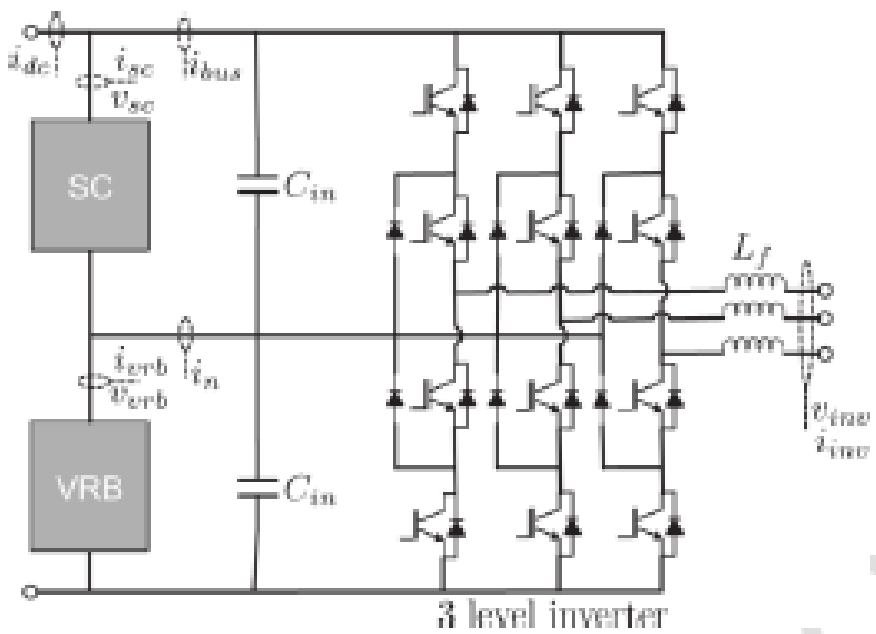

Figure 6. Three-Level Neutral Point Clamped Converter with its associated hybrid ESS.

The obtained experimental results have validated the proposed control algorithm and have shown that the proposed topology is able to respond to the requirements of the microgrid application, i.e. to have a high power density, a high energy density and a fast response time [62]. Figure 7 shows the results of a case study where a variable power is injected in the DC bus of the 3LNPC converter (Figure 7a). As it can be seen from Figure $7 \mathrm{~b}$, the system is able to correctly divide the power between the $\mathrm{SCs}$ and the $\mathrm{VRB}$ according to the frequency. Fast power variations are faced by the $\mathrm{SCs}$ and the slow power variations by the VRB.

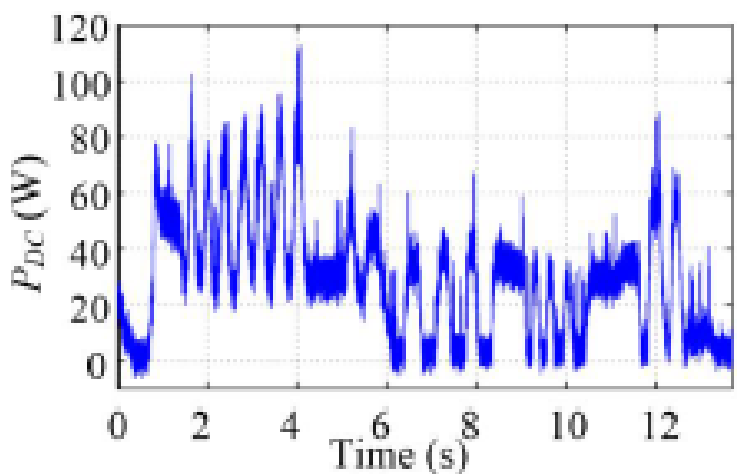

(a)

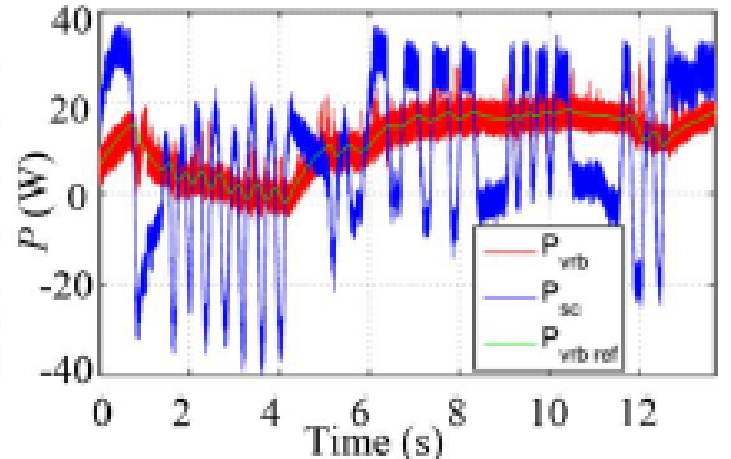

(b)

Figure 7. (a) The power injected in the DC bus. (b) The power of the VRB, SCs and the reference power of the VRB.

\subsection{Wireless communication for MG management in islanded mode}

Figure 8 depicts the architecture which has been used to test the wireless measuring part of a MG control system in the frame of a $\mathrm{PhD}$ carried out with the UPV/EHU. Included in a zigbee cheap communication network, the measuring system is connected to the output of the Windy Boy (WB) inverter that is supplied by the WT emulator [63]. 
Camblong H., Curea O., Etxeberria A., Llaria A., Hacala A., "Research experimental platforms to study microgrids issues". IJDEM, 2015, Online ISSN 1955-2505, Springer Paris, DOI 10.1007/s12008-015-0288-x

At $t=12 \mathrm{~s}$, the WB starts injecting power in the grid, until its disconnection $48 \mathrm{~s}$ later.

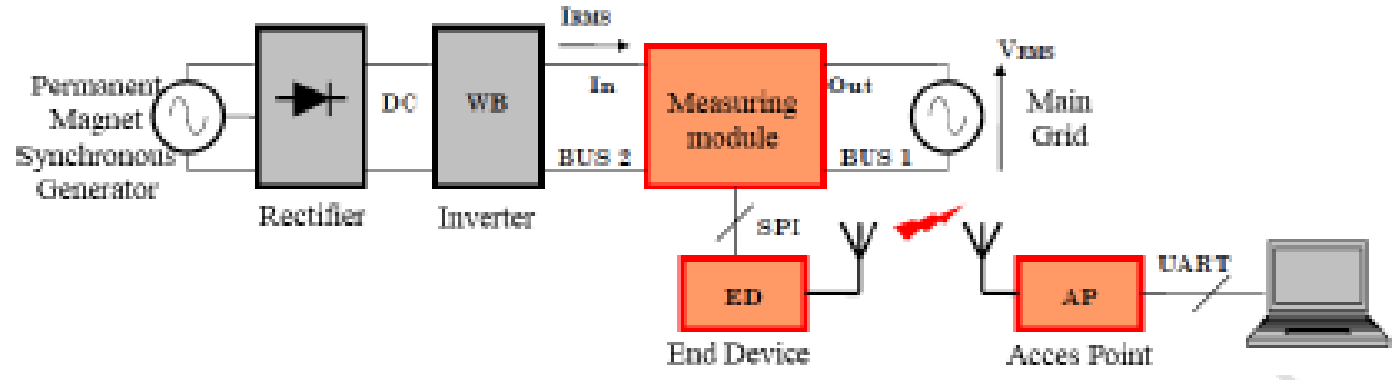

Figure 8. Experimental assembly for wireless communication testing.

Figure 9 shows the measure of the RMS current injected in the main grid by the wind turbine emulator during the carried out experiment, with the WB operating at $1000 \mathrm{~W}$.

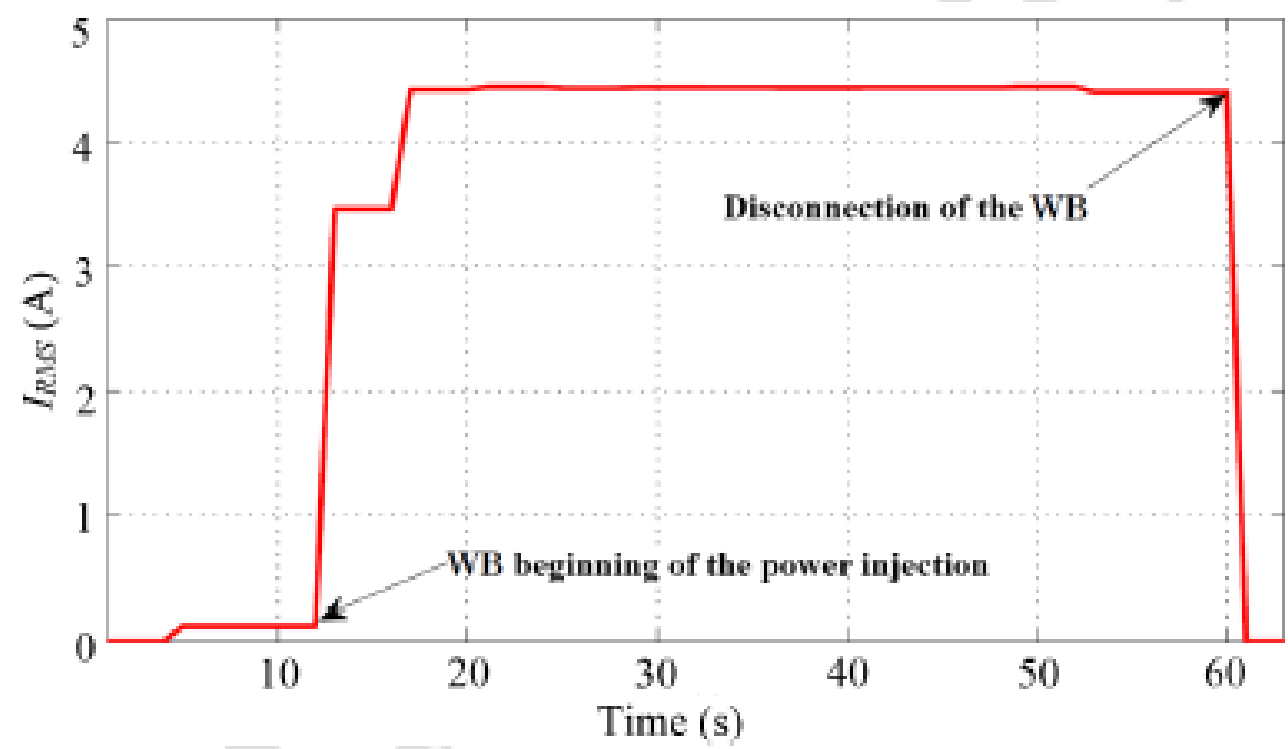

Figure 9. Current injected in the main grid by the wind turbine emulator.

\subsection{Example of industrial project}

Since its creation, the EneR-GEA platform has been continuously enriched with new equipment allowing the realization of specific experiments in connection with research projects on one hand and industrial projects on the other hand. The design of the platform allows great flexibility facilitating the addition of new equipment.

One should note that industrial projects are mainly carried out with small and medium companies as they do not have the in-house research teams or equipment that are needed to carry out experiments.

A project is detailed below as an example. For confidentiality reasons, company name is not mentioned.

The initial need of the company was to provide renewable power generation systems that could be installed in micro-grids supplied by diesel generators. Their first idea was 
Camblong H., Curea O., Etxeberria A., Llaria A., Hacala A., "Research experimental platforms to study microgrids issues". IJIEM, 2015, Online ISSN 1955-2505, Springer Paris, DOI 10.1007/s12008-015-0288-x

to replace conventional electronic DC/AC converters with electric machines (DC motor and synchronous generator).

While the performance of electric machines is lower than that of electronic converters, their use has the advantage of reduced maintenance, greater robustness and presence of qualified personnel on sites. The developed system should be installed, without causing disturbance, on sites powered by diesel generators.

The company and the EneR-GEA team have work together to study the feasibility of the proposed system. An interactive engineering method was used in the way that all project stakeholders were involved in all phases of the study: the proposed architecture and analyses carried out by the researchers were systematically confronted with industrial needs (implementation constraints, budget constraints...) and a team of students was in charge of some modelisation work. The result of the study is an optimized architecture and an experimental validation of the feasibility of the system.

\section{Planned improvements, studies and experiments in the EneR-GEA platform}

The next subsections present some planned improvements, studies and experiments in the EneR-GEA platform.

\subsection{ESSs and DG emulation in the MG}

Due to the voltage level limitations of the small scale ESS aforementioned, it is not possible to carry out experimental tests in standard voltage levels (230 VRMS). In order to overcome this limitation, the EneR-GEA group has bought two 4-quadrant power amplifiers (unit PAS1000 of the manufacturer Spitzenberger and Spies) that will allow emulating at higher voltage and power levels the operation of several storage systems. The dynamic models of the ESS will be executed in real-time in the hardware-in-theloop system, and the analog signals generated by this system will be amplified and interfaced with the rest of the MG by the mentioned power amplifiers.

On the other hand, in the frame of a $\mathrm{PhD}$ in co-supervision between the UPV/EHU and the UBX, and in collaboration with the University of Perugia (Italy), a hybrid FCMT generator emulator is being developed. The outputs of the emulator are two DC buses. The ARCEL 3LNPC converter will be the interface between these buses and the 3 -phase AC bus of the platform. The converter will allow controlling DC buses and AC voltage with the aim of minimizing harmonic distortions and facing unbalanced loads.

\section{2. "Digital ecosystem" concept for a better management of MGs}

With the emergence of digital networked environments, a new form of collaboration has shown up enabling components not only to interact easily and quickly but also to think globally since each component activities have a direct influence on the entire environment. This is the case of the power system where each node can become smart, 
Camblong H., Curea O., Etxeberria A., Llaría A., Hacala A., 'Research experimental platforms to study microgrids issues". IIDEM, 2015, Online ISSN 1955-2505, Springer Paris, DOI 10.1007/s12008-015-0288-x

autonomous, and produce and/or consume energy.

A PhD is being carried out with the UPV/EHU and the University of Pau and Pays de l'Adour (UPPA, France) on this topic. Its aim is to design MGs-oriented digital ecosystems able to detect appropriate component behaviors under various circumstances (important events, weather variation, islanding operation, reconnection to the main grid, etc.) and also provide relevant services (better distributed generation scheduling and management, economic optimization, minimization of the impact on the environment, predicting energy consumption, etc.). The framework to be provided will have to be fully distributed, secure and with simplified interfaces for easy plugging to heterogeneous sources. Currently, game theory is being studied to model and optimize the operation of a microgrid.

\subsection{Robust control of a WT associated to an ESS in island grids}

This project which will be carried out in collaboration with the UBX and the UPV/EHU aims to explore robust control of a WT associated to an ESS in an island grid. To meet the quality constraint on the produced energy, it is essential to associate ESSs to intermittent productions. To do this, the use of a ESSs connected to the DC bus of a back-to-back converter of a WT will be studied. The active and reactive powers exchanged with the grid will be controlled by a robust control method such as CRONE control. This choice is imposed by the variations of the system's operating point leading to dynamic behavior variations of the controlled system. The developed control strategies will be implemented on the EneR-GEA experimental platform This way, now, a back to back converter is being installed and put in operation in order to connect the wind turbine generator (Figure 3 ) to the microgrid.

\subsection{HES management}

The objective of this $\mathrm{PhD}$ carried out with the Superior Institute of Informatics and the National Engineering School (ENIT) of Tunis (Tunisia) and the UPV/EHU will be to operate optimally a HES, composed by PV panels, a small WT and batteries, included in a MG. The management will be carried out by multi agent systems in order that the HES will be able to provide AS to the MG which will be connected or islanded from the utility. The $\mathrm{PhD}$ is being focused specially to the safety, reliability and robustness of microgrids operation [64].

\section{Conclusions}

MG concept and associated technologies have to mature. Many issues have still to be resolved or developed in order to consider MGs as some efficient tools which will contribute to the transformation of nowadays grids to the future smartgrids.

Innovative solutions related to these issues are usually tested through simulations and 
Camblong H., Curea O., Etxeberria A., Llaria A., Hacala A., 'Research experimental platforms to study microgrids issues". IJDEM, 2015, Online ISSN 1955-2505, Springer Paris, DOI 10.1007/s12008-015-0288-x

experiments before being implemented in the real grid. Many experimental platforms of different types exist all over the world to carry out this kind of experiments. EnerGEA platform from ESTIA engineering school is one of them. It is a low power and flexible platform containing real and emulated components. It is easily reconfigurable.

Some research results have already been validated there. It is an open-access platform and as until now, foreseen planned improvements and tests will be carried out next years in collaboration with different universities.

\section{Acknowledgments}

The experimental EneR-GEA platform described in this paper has been supported, above all, by the Regional Council of Aquitaine, the CNRS and the French government in the frame of the MATSYME project.

\section{References}

[1] Momoh J. Smart Grid. Fundamentals of design and analysis. IEEE press series on power engineering, series editor El-Hawary ME, Wiley, 2012.

[2] Lasseter RH, Akhil A, Marnay C, Stephens J, Dagle J, Guttromson R, Meliopoulous A, Yinger R, Eto J. The CERTS Microgrid Concept, White Paper for Transmission Reliability Program, Office of Power Technologies, U.S. Department of Energy, 2002.

[3] Xingguo T, Qingmin L, Hui W. Advances and trends of energy storage technology in Microgrid. Int J Elec Power 2013; 44: 179-91.

[4] Lasseter R. MicroGrids. IEEE Power Engineering Society Winter Meeting 2002, New York, USA.

[5] Pecen R, Nayir A. Design and implementation of a $12 \mathrm{~kW}$ wind-solar distributed power and instrumentation system as an educational testbed for electrical engineering technology students. 2010 International Symposium on Modern Electric Power Systems (MEPS). Wroclaw, Poland.

[6] Abu-Sharkh S and al. Can microgrids make a major contribution to UK energy supply? Renew Sust Energ Rev 2006; 10: 78-127.

[7] Costa PM, Matos MA. Assessing the contribution of microgrids to the reliability of distribution networks. Electr Pow Syst Res 2009; 79: 382-9.

[8] Sanseverino ER, Di Silvestre MI, Ippolito MG, De Paola A, Re GL. An execution, monitoring and replanning approach for optimal energy management in microgrids. Energy 2011; 36: 3429-36.

[9] Alvarez E, Campos AM, Arboleya P, Gutiérrez AJ. Microgrid management with a quick response optimization algorithm for active power dispatch Int J Elec Power 2012; 43: 465-73.

[10] Mohammadi S, Mozafari B, Soleymani S. Optimal operation management of microgrids using the point estimate method and firefly algorithm while considering 
Camblong H., Curea O., Etxeberria A., Llaria A., Hacala A., "Research experimental platforms to study microgrids issues". IJDEM, 2015, Online ISSN 1955-2505, Springer Paris, DOI 10.1007/s12008-015-0288-x

uncertainty. Turk J Elec Eng \& Comp Sci 2014; 22: 735-53.

[11] Marzband M, Sumper A, Ruiz-Álvarez A, Domínguez-Garcia JL, Tomoiaga B. Experimental evaluation of a real time energy management system for stand-alone microgrids in day-ahead markets. Appl Energ 2013; 106: 365-76.

[12] Logenthiran T, Srinivasan D, Khambadkone AM. Multi-agent system for energy resource scheduling of integrated microgrids in a distributed system. Electr Pow Syst Res 2011; 81: 138-48.

[13] Kyriakarakos G, Dounis AI, Arvanitis KG, Papadakis G. A fuzzy logic energy management system for polygeneration microgrids. Renew Energ 2012; 41: 315-27.

[14] Braun M Technological control capabilities of DER to provide future ancillary services. Int. J. Distrib. Energy Resour 2007; 3(3): 191-206.

[15] Lopes JAP, Hatziargyriou N, Mutale J, Djapic P, Jenkins N. Integrating distributed generation into electric power systems: a review of drivers, challenges and opportunities. Electr Pow Syst Res 2007; 77(9): 1189-203.

[16] Macureira AG, Lopes JAP. Ancillary services market framework for voltage control in distribution networks with microgrids. Electr Pow Syst Res 2012; 86: 1-7.

[17] Paiva JE, Carvalho AS. Controllable hybrid power system based on renewable energy sources for modern electrical grids. Renew Energ 2013; 53: 271-79.

[18] San Martin J, Zamora I, San Martín JJ, Aperribay V, Eguia P. Hybrid fuel cells technologies for electrical microgrids. Electr Pow Syst Res 2010; 80: 993-1005.

[19] Karabiber A, Keles C, Kaygusuz A, Baykant Alagoz B. An approach for the integration of renewable distributed generation in hybrid $\mathrm{DC} / \mathrm{AC}$ microgrids. Renew Energ 2013; 52: 251-9.

[20] Llaria A, Curea O, Jiménez J, Camblong H. Survey on microgrids: Unplanned islanding and related inverter control techniques. Renew Energ 2011; 36: 2052-61.

[21] Bower W, Ropp M. Evaluation of islanding detection methods for photovoltaic utility-interactive power systems. International Energy Agency, 2002. Technical report IEA PVPS T5-09.

[22] Zeineldin $H A$ Qef droop curve for facilitating islanding detection of inverterbased distributed generation. IEEE Trans Power Electron 2009; 24: 665-73.

[23] IEEE standard for interconnecting distributed resources with electric power systems. Standard IEEE 1547-2003.

[24] IEEE recommended practice for utility interface of photovoltaic (PV) systems. Standard IEEE 929-2000.

[25] Inverters, converters, and controllers for use in independent power systems. Standard UL 1741, 2004.

[26] Indu Rani B, Srikanth M, Saravana Ilango G, Nagamani C. An active islanding detection technique for current controlled inverter. Renew Energ 2013; 51: 189-96.

[27] Xiao Z, Li T, Huang M, Shi J, Yang J, Yu J, Wu W. Hierarchical MAS based 
Camblong H., Curea O., Etxeberria A., Llaria A., Hacala A., 'Research experimental platforms to study microgrids issues". IJIDEM, 2015, Online ISSN 1955-2505, Springer Paris, DOI 10.1007/s12008-015-0288-x

control strategy for microgrid. Energies 2010; 2: 1622-38.

[28] Kyriakarakos G, Piromalis DD, Dounis AI, Arvanitis KG, Papadakis G. Intelligent demand side energy management system for autonomous polygeneration microgrids. Appl Energ 2013; 103: 39-51.

[29] Vandoorn TL, De Kooning JDM, Meersman B, Vandevelde L. Review of primary control strategies for islanded microgrids with power-electronic interfaces. Renew Sust Energ Rev 2013; 19: 613-28.

[30] Lopes JAP, Moreira CL, Macureira AG. Defining Control Strategies for MicroGrids Islanded Operation. IEEE Trans Power Sys 2006; 21(2): 916-24.

[31] Rabiee A, Khorramdel H, Aghaei J. A review of energy storage systems in microgrids with wind turbines. Renew Sust Energ Rev 2013; 18: 316-26.

[32] Zamora R, Srivastava AK Controls for microgrids with storage: Review, challenges, and research needs. Renew Sust Energ Rev 2010; 14: 2009-18.

[33] Pascual J, Sanchis P, Marroyo L. Implementation and control of a residential electrothermal microgrid based on renewable energies, a hybrid storage system and demand side management. Energies 2014; 7: 210-237.

[34] Samineni S, Johnson BK, Hess HL, Law JD. Modeling and analysis of a flywheel energy storage system for voltage sag correction. IEEE T Ind Appl, 2006; 42(1): 42-52.

[35] Sofla MA, Gharehpetian GB. Dynamic performance enhancement of microgrids by advanced sliding mode controller. Int J Elec Power 2011; 33: 1-7.

[36] Shahnia F, Majumder R, Ghosh A, Ledwich G, Zare F. Operation and control of a hybrid microgrid containing unbalanced and nonlinear loads. Electr Pow Syst Res 2010; 80: 954-65.

[37] Fortescue CL. Method of symmetrical coordinates applied to the solution of polyphase networks. AIEE Trans 1918; 37: 1027-140.

[38] Soto D, Edrington C, Balathandayuthapani S, Ryster S. Voltage balancing of islanded microgrids using a time-domain technique. Electr Pow Syst Res 2012; 84: $214-$ 23 .

[39] Hatziargyriou N, Asano H, Iravani R, Marnay C. Microgrids. IEEE Power \& Energy Magazine 2007; 5: 78-94.

[40] Kroposki B, Lasseter R, Ise T, Morozumi S, Papatlianassiou S, Hatziargyriou N. Making microgrids work. IEEE Power \& Energy Magazine 2008; 6: 40-53.

[41] Bames M. and al. Real-world microgrids - an overview. IEEE International Conference on System of Systems Engineering, 2007, San Antonio, USA.

[42] Licula N, Rajapakse A. Microgrids research: a review of experimental microgrids and test system. Renew Sust Energ Rev 2011; 15: 186-202.

[43] Planas E, Gil-de-Muro A, Andreu J, Kortabarria I, Martinez de Alegría I General aspects, hierarchical controls and droop methods in microgrids: a review. Renew Sust Energ Rev 2013; 17: 147-59. 
Camblong H., Curea O., Etxeberria A., Llaria A., Hacala A., "Research experimental platforms to study microgrids issues". IJDEM, 2015, Online ISSN 1955-2505, Springer Paris, DOI 10.1007/s12008-015-0288-x

[44] Barnes $M$ and al. Microgrid laboratory facilities. International Conference on Future Power Systems 2005, Amsterdam, Netherlands.

[45] Gomis-Bellmunt O, Sumper A, Colet-Subirachs A, Ruiz-Alvarez A, AlvarezCuevas-Figuerola F, Sudria-Andreu A. A utility connected microgrid based on power emulators. Power and Energy Society General Meeting, 2011, Detroit, USA.

[46] Nichols D, Stevens J, Lasseter R, Eto J, Vollkommer H. Validation of the CERTS microgrid concept: the CEC/CERTS microgrid testbed. IEEE Power Engineering Society General Meeting, 2006, Montreal, Canada.

[47] Abbey C, Katiraei F, Brothers C, Dignard-Bailey L, Joos G. Integration of distributed generation and wind energy in Canada. IEEE Power Engineering Society General Meeting, 2006, Montreal, Canada.

[48] Peralta J, Iosfin H, Tang X. BC Hydro perspective on distribution islanding for customer reliability improvement. CIGRE/IEEE PES Joint Symposium Integration of Wide-Scale Renewable Resources Into the Power Delivery System 2009, Calgary, Canada.

[49] Morozumi S. Micro-grid demonstration projects in Japan. 4th IEEE Power Conversion Conference, 2007, Nagoya, Japan.

[50] Morozumi S, Nakama H, Inoue N. Demonstration projects for grid connection issues in Japan. Elektrotechnik und Informationstechnik 2008; 125: 426-31.

[51] Kojima Y, Koshio M, Nakamura S, Maejima H, Fujioka Y, Goda T. Demonstration project in Hachinohe: microgrid with private distribution line. IEEE International Conference on System of Systems Engineering, 2007, San Antonio, USA.

[52] Hirose K, Takeda T, Muroyama S. Study on field demonstration of multiple power quality levels system in Sendai 28th International Telecommunications Energy Conference (INTELEC), 2006, Providence, USA.

[53] Meiqin M, Ming D, Jianhui S, Chang L, Min S, Guorong Z. Testbed for microgrid with multi-energy generators. Canadian Conference on Electrical and Computer Engineering (CCECE), 2008, Ontario, Canada.

[54] Advanced architectures and control concepts for More Microgrids. More Microgrids Consortium, Technical Report, 2009.

[55] Bracco S, Delfino F, Pampararo F, Robba M, Rossi M. The University of Genoa smart polygeneration microgrid test-bed facility. The overall system, the technologies and the research challenges. Renew Sust Energ Rev 2013; 18: 442-59.

[56] Curea O, Vechiu I, Camblong H. Design of a Test Bench for the Analysis of a Hybrid Power System. EWEC 2004, London, UK

[57] Curea O, Vechiu I, Marin D, Camblong H, Dakyo B. Small-Scale Test Bench of a Hybrid Power System. EPE 2005, Dresden, Germany.

[58] Curea O, Camblong H, Llaria A, Vechiu I, Marin D. Increasing Public Awareness of Renewable Energies and Electrical Consumption Reduction: Estia's Approach The 
Camblong H., Curea O., Etxeberria A., Llaria A., Hacala A., "Research experimental platforms to study microgrids issues". IJIEEM, 2015, Online ISSN 1955-2505, Springer Paris, DOI 10.1007/s12008-015-0288-x

International Scientific Journal for Alternative Energy and Ecology 2008; 5: 103-10.

[59] Vechiu I, Camblong H, Tapia G, Dakyo B, Curea O. Control of a Four-Leg Inverter for Hybrid Power System Applications with Unbalanced Load. Energ Convers Manage $2007 ; 48(7): 2119-28$.

[60] Vechiu I, Curea O, Camblong H. Transient Operation of a Four-Leg Inverter for Autonomous Applications with Unbalanced Load. IEEE Trans Power Electronics 2010; 25(2): 399-407.

[61] Etxeberria A, Vechiu I, Camblong H, Vinassa JM. Comparison of Three Topologies and Controls of a Hybrid Energy Storage System for Microgrids. Energ Convers Manage 2012; 54(1): 113-21.

[62] Etxeberria A. Microgrid Hybrid Energy Storage Integration and Control using a Three-Level NPC Converter. PhD, Université Bordeaux 1, Bordeaux, France 2012.

[63] Llaria A, Curea O, Jimenez J, Martin J, Zuloaga A. Wireless communication system for microgrids management in islanding. 14th European Conference on Power Electronics and Applications (EPE), 2011. Birmingham, England.

[64] Boussaada Z., Curea O., Camblong H., Bellaaj Mrabet N., Hacala A., "Multi-agent systems for the dependability and safety of microgrids". IJDEM 2014, DOI $10.1007 / \mathrm{s} 12008-014-0257-9$ 